\title{
HEGEL E A HISTÓRIA MUNDIAL
}

Leonardo Alves Vieira*

RESUMO - Neste estudo, a história mundial, tal como concebida por Hegel, é analisada a partir dos §§ 330-360 da Filosofia do Direito. Em seguida, procura-se coordenar estes parágrafos com as teses de Kant sobre a guerra e a paz. Finalmente, as abordagens de Kant e de Hegel são retomadas à luz do estudo de Hobsbawm sobre o cenário político internacional nos séculos 20 e 21 .

PALAVRAS-CHAVE - Hegel. Filosofia do direito. História mundial.
ABSTRACT - In this study, the history of the world as conceived by Hegel is investigated on the basis of $\S \S 330-360$ of his Philosophy of Law. Hegel's theory is afterwards linked to Kant's theses concerning the pax perpetua. Finally, Kant's and Hegel's approaches on war and peace shall be assessed by comparing them to Hobsbawm's views on the political international scene of the $20^{\text {th }}$. and $21^{\text {st }}$. Centuries.

KEY WORDS - Hegel. Philosophy of law. World history.

A abordagem da história mundial na ótica de Hegel (1775-1831) é muita complexa. Na verdade, ela é objeto de uma filosofia da história, a qual é, antes de tudo, uma filosofia. Em razão disso, sua peculiar interpretação dessa história não pode estar desvinculada do contexto mais amplo de seu sistema de filosofia, tal como Hegel deixa bem claro no último parágrafo do prefácio às Linhas fundamentais da Filosofia do Direito ou Direito Natural e Ciência do Estado em esboço (1821), no qual ele fala do "tratamento científico da coisa", bem como também na introdução, em cujo § 2 a "ciência do Direito" é dita explicitamente ser uma "parte da Filosofia". Não é o caso, aqui, de trazer à luz esse imenso contexto sistemático, visto que tal estudo extrapolaria os limites deste trabalho. ${ }^{1}$ Minha intenção é, pois, limitar-me aos §§ 330-360 da Filosofia do Direito, procurando, deste modo, corresponder ao espírito do Congresso: "Clássicos da Filosofia Alemã 2002 - Filosofia do Direito de Hegel", ${ }^{2}$ que se dedica aos temas tratados nesta obra. ${ }^{3}$

* Professor da UFMG.

1 A esse propósito, v. Vieira (1996).

De 1 a 4 de abril de 2002, Instituto Goethe, Porto Alegre, em promoção conjunta do referido Instituto e do Programa de Pós-Graduação em Filosofia da PUCRS.

3 Além da Filosofia do Direito, a única outra obra de Hegel, excepcionalmente citada, será a Ciência da Lógica, cuja estreita vinculação com a Filosofia do Direito também não é negada por Hegel. V. prefácio, 12s. Com exceção do prefácio, do qual serão citadas as páginas, as passagens da Filosofia do Direito serão referidas de acordo com os respectivos parágrafos e, se for o caso, com as respectivas observações e respectivos adendos.

\begin{tabular}{|l|l|l|l|l|l|}
\hline VERITAS & Porto Alegre & v. 51 & n. 1 & Março 2006 & p. 69-83 \\
\hline
\end{tabular}


Foi também meu interesse não me restringir ao pensamento hegeliano, no que se refere à temática em questão. O primeiro interlocutor chamado para o debate com Hegel foi Kant (1724-1804), já que o próprio Hegel o cita, apontando a sua tese de uma Federação de Estados como uma proposta não aceita por ele. Ao mesmo tempo, com a intenção de perscrutar a pertinência das teses de Hegel e Kant, um outro interlocutor e, desta vez, um contemporâneo nosso, é chamado. Trata-se de Hobsbawm (1917- ), cuja análise da guerra, enquanto uma verdadeira epidemia do século XX, oferece valiosíssimas contribuições, a fim de avaliar as observações de Hegel e Kant acerca da história mundial e do papel da guerra nela.

Em razão disso, a primeira parte tem como objeto as relações entre os Estados, das quais surge a tese hegeliana da história mundial enquanto tribunal para julgar os povos. A segunda e terceira partes dedicar-se-ão à própria história mundial, buscando, nos limites deste trabalho, apresentar os traços principais que a caracterizam. Finalmente, na quarta parte, avaliações sobre os argumentos de Hegel e Kant serão feitas, tomando como linha mestra as observações de Hobsbawm sobre o sangrento século XX e o início do século XXI.

\section{As relações interestatais}

A abordagem da história mundial na Filosofia do Direito de Hegel é tratada, de acordo com a economia e lógica internas do texto, como resultado do Direito estatal externo (das äussere Staatsrecht). Em razão disso, tal abordagem pressupõe o Estado e sua organização interna, bem como a relação entre os Estados. Não por acaso, Hegel, no primeiro parágrafo dedicado à história mundial, qualifica-a como a negação do que ocorre nas relações entre os Estados. Ela é considerada como o tribunal (§ 341), no qual os Estados serão julgados, de acordo com o Direito ${ }^{4}$ daquele que nela se realiza (§ 340), em oposição à ausência de um "poder reconhecido por cada Estado singular" ou de um "pretor" (§ 333, obs.; § 330 e adendo) acima das partes conflitantes no teatro das relações internacionais e capaz de dirimir pacificamente as suas interações, fazendo prevalecer o que é "em si Direito".

Na ausência de um acordo ou consenso (Einstimmung - § 333, obs.; Übereinkunft - § 334) no "jogo" (§ 340) entre os atores estatais, prevalece a vontade particular de cada Estado, baseada nos mais distintos aspectos: religiosos, morais, culturais, sociais, econômicos, políticos, militares, etc., de tal forma que a massa de interesses conflitantes será carregada pelas forças da guerra. Daí, portanto, que a inexistência de um poder universalmente reconhecido pelos Estados leva-os a uma situação semelhante àquela do estado de natureza entre os indivíduos: ao estado de natureza entre os Estados (§ 333). Não por acaso, a guerra é qualificada como "estado (Zustand) da ausência do Direito (Rechtlosigkeit), da violência e da contingência" (§ 338).

4 As questões relativas a quem efetiva tal Direito (o sujeito deste Direto) e ao objeto deste Direito serão discutidas mais adiante. 
Também de forma semelhante ao estado de natureza entre os indivíduos, ${ }^{5}$ a guerra entre os atores internacionais deve ser abandonada, "deve ser algo passageiro" (ein Vorübergehensollendes, § 338). A guerra não deve acontecer, mas como acontece com todo dever-ser, aquilo que não deve ser pode, no entanto, ser. A contingência - a história mundial não pode prescindir da contingência, da vontade particular de cada Estado e de cada indivíduo, vontades sujeitas ao ser e não-ser da escolha - ínsita em toda vontade particular de um determinado Estado (§ 333, obs.) se opõe à objetividade e universalidade da "forma do dever-ser" (Form des Sollens, § 330) externalizada pelo Direito, assim como o imperativo categórico, objetiva e universalmente válido, não pode anular a contingência da vontade subjetiva e transformar o que é prescritivo (dever ser assim) em algo descritivo (ser assim). ${ }^{6}$

Neste contexto, vale a pena coordenar as reflexões de Hegel com as de Kant, uma vez que o próprio Hegel liga a sua tese como uma alternativa à posição de Kant. A referência ao texto de Kant sobre a Paz Perpétua na observação ao § 333, em razão mesmo da natureza minimalista dessa referência, não consegue, contudo, evidentemente, trazer à luz as nuanças da argumentação de Kant e, mesmo o que será apresentado aqui, não poderá descer aos detalhes de ambas as argumentações. Apesar disso, tenho a intenção de chamar a atenção para as motivações que conduziram Hegel a não aceitar a argumentação de Kant favorável à Paz Perpétua "mediante uma Federação de Estados" (durch einen Staatenbund).

Essa federação baseia-se em um consenso (Einstimmung) entre os Estados, cujas vontades, por sua vez, sujeitas à contingência, constituem uma garantia bastante volátil e instável para uma resolução de conflitos em consonância com as exigências do Direito. Em razão dessa contingência, a relação entre os Estados pode abrigar tanto o que é "em si Direito", "o dever-ser", quanto a "violência" e a "guerra" (§ 330, adendo; § 334). A oscilação e indeterminação entre Direito e guerra, justiça e violência, dever-ser e ser, nas relações internacionais, constituem contingência (Zufälligkeit) ${ }^{7}$ no preciso sentido da incapacidade da vontade, seja a

5 A relação entre a pessoa efetiva enquanto singular, por um lado, e o Estado, por outro, é explicitamente feita no § 331, obs. A conseqüência também é óbvia: o reconhecimento entre os Estados também deve ser recíproco, assim como entre os indivíduos. Não deve ser esquecido o fato de que a vontade livre em si e para si, princípio volitivo organizador do direito abstrato, da moralidade e eticidade, não elimina, mas nega e conserva os momentos volitivos que a antecedem, a saber, (1) vontade imediata e natural e (2) vontade enquanto arbítrio, responsáveis por uma organização das ações com base na particularidade em detrimento do universal, ao passo que somente a vontade livre em si e para si encontra-se em condições de articular apropriadamente o singular e o universal (Introdução, §§ 10-24). São a vontade imediata e o arbítrio aqueles que promovem a contingência e a cruz (a negação do universal), cuja suprassunção dialética é a liberdade racional e efetivamente realizada, "a rosa na cruz do presente", segundo outra famosa metáfora do prefácio, 26.

6 V. a distinção feita por Kant entre lei moral e imperativo categórico: Kant, KpV, A 57; v. tb. Herrero (2001).

7 Vale a pena lembrar a definição técnica de contingência na Ciência da Lógica: "A unidade entre possibilidade e efetividade (Wirklichkeit) é a contingência. O contingente é um efetivo que é simultaneamente determinado apenas como possível, cujo outro ou contrário também é. Portanto, esta efetividade é mero ser ou existência, mas posta em sua verdade, de ter o valor de um ser posto ou da possibilidade" (WL II, 205). 
individual, seja a estatal, em fixar-se em apenas um dos extremos dos seus elementos de motivação: ela pode admitir, como seu fator de determinação, tanto a universalidade da lei quanto o seu contrário, a saber, a particularidade dos interesses privados. É justamente também nesse sentido que o Sollen ${ }^{8}$ é contingente, já que ele pressupõe, como possibilidade, o desviar-se daquilo que ele exige. A guerra, enquanto resolução de conflitos, não baseada no Direito, tem lugar precisamente em razão, por assim dizer, dessa "díade indeterminada" vivenciada pelas vontades de Estados e indivíduos oscilando entre a díke do dever-ser e a hýbris da violência.

Hegel, porém, não leva em conta, nessa análise, a oscilação experimentada pelo próprio Kant, nos textos Sobre o adágio: isto pode estar correto na teoria, mas não serve para a prática (1793) e Para a Paz Perpétua (1795), ${ }^{9}$ entre a Constituição Cosmopolita (weltbürgerliche Verfassung, TP, A 279), Estado Universal dos Povos ou simplesmente Estado dos Povos (allgemeiner Völkerstaat; Völkerstaat, TP, A 284; EF, B 30), ou ainda República Mundial (Weltrepublik, EF, B 38), de um lado, e um estado (Zustand) jurídico da Federação, de acordo com um Direito das Gentes comumente acordado (ein rechtlicher Zustand der Föderation nach einem gemeinschaftlich verabredeten Völkerrecht; TP, A 279), Federalismo de Estados Livres (Föderalism freier Staaten; EF, 30), ou simplesmente Federação dos Povos (Völkerbund, EF, B 30), de outro. ${ }^{10}$ No texto de 1795, Kant adota a tese de uma Federação dos Povos, visto que ela garante a soberania dos Estados livremente associados nesta Federação, bem como ela evitaria "o mais terrível despotismo" ou "o despotismo sem alma", o qual poderia advir de uma República Mundial, concentrando em si todos os mecanismos do poder em escala planetária (TP, A 279; EF, B 63). No entanto, ainda no texto sobre a Paz Perpétua, a República Mundial é qualificada como uma idéia positiva, em contraste com a Federação dos Povos, caracterizada como substituto negativo (EF, B 38), talvez por considerar aquela como a contraparte juridicamente positiva, no campo das relações internacionais, ao que o Estado é no campo das relações interindividuais - o que deve ser do ponto de vista da razão, em contraste com o sucedâneo juridicamente negativo da Federação dos Povos, enquanto algo politica, i. e., factivelmente mais plausível de ocorrer nas circunstâncias de então. ${ }^{11}$

8 Obviamente, o dever-ser, o Sollen, no sentido kantiano, não tem este caráter de contingência, já que ele expressa uma "lei prática incondicionada" (KpV, A 52s). Evidentemente, não há discordância, da parte de Hegel, acerca dessa necessidade moral. A contingência apontada por Hegel reside no fato de que o dever-ser, justamente por comportar uma necessidade do dever-ser e não a do ser, admite alternativa(s) ao que deve ser. Este possível desvio do imperativo categórico já fora apontado por Kant: o "dever-ser expressa uma espécie de necessidade e conexão com razões, uma espécie que não ocorre em toda a natureza. O entendimento pode somente conhecer desta [natureza, adendo de LAV], o que é aí ou o que foi ou o que será. É impossível que algo aí deva ser de modo diferente" (KrV, B 5750). Essa espécie de volatilidade existente no campo da liberdade é, no entan-

to, aproveitada diferentemente por Kant e Hegel, como se verá ao longo do texto.

9 Sobre a Paz Perpétua, v. Rohden (1997); Merkel, R. e Wittmann, R. (1996); Lutz-Bachmann, M. e Bohman, J. (1996).

10 Sobre as questões suscitadas por essa argumentação de Kant, v. Habermas (1996).

11 Sobre o viés político do texto de Kant sobre a Paz Perpétua, v. Gerhardt (1995). 
De fato, a lógica estrita e rigorosa do contrato social, entendido como uma idéia da razão, não pode deixar nenhuma lacuna para ser ocupada pelo estado de natureza, seja na esfera intra-estatal, seja na interestatal. ${ }^{12}$ Daí, certamente, advém o caráter positivo da República Mundial, por ser esta o sistema jurídicopolítico de alcance planetário que "domestica" o estado de natureza entre os Estados, ao passo que a Federação dos Estados, ao admitir a pluralidade de Estados, consensual e livremente associados, ainda é vítima de instabilidade e impregnada de características de relações típicas do estado de natureza, constituindo-se como uma espécie de propedêutica à situação definitiva que deve finalmente vigorar.

A história mundial tematizada por Hegel guardará uma certa semelhança com a Federação dos Povos de Kant, na medida em que ambas preservam a pluralidade de Estados, já que Hegel, ao fazer uma rememoração do devir da humanidade, tal como ela se organizou na forma de Estados, não pretendia apontar para o vir-a-ser futuro dos seres humanos, associados em um único Estado dos Povos. Embora guardando semelhanças, as relações entre indivíduos e Estados e as entre Estados não são absolutamente idênticas, pois os indivíduos "têm acima de si um tribunal que realiza aquilo que é em si Direito" (§ 330, adendo), enquanto que os Estados, na medida em que têm uma "independência soberana" (§ 331), constituem "o poder absoluto na terra" (§ 331). Evidentemente, diante desse contexto argumentativo, compreende-se, de um lado, o caráter contingente da Federação dos Povos e, de outro, a recusa, por parte de Hegel, de um Estado Universal dos Povos. ${ }^{13}$

Ainda no contexto da observação do § 333, Hegel também não considera em sua crítica a Kant o papel daquilo que Kant denomina, ora natureza humana (TP, A 278) ou simplesmente natureza (EF, B 47), ora providência (TP, A 278; EF, B 47), no sentido de favorecer a institucionalização da Paz Perpétua, bem como não leva em conta os meios investigados por Kant para a efetivação da Paz Perpétua. Em Para a Paz Perpétua, Kant prefere o termo natureza, visto que ele é "mais apropriado para os limites da razão humana" e "mais modesto do que a expressão de uma providência incognoscível para nós” (EF, B 51s). A natureza, providencialmente interpretada, e os seus meios dizem respeito à garantia para a realização da Paz Perpétua. Natureza (EF, B 47ss; TP, A 279ss) tem em vista, aqui, uma causa suficientemente inteligente orientada para a consecução do télos da humanidade, prescrito pela razão (EF, B 51), mas por ela - ou, pelo menos, pela grande maioria dela - não perseguido de "boa vontade" (TP, A 280), ou, então, por ela buscado "mesmo contra a vontade" (TP, A 279). Portanto, "aquilo que o ser humano deveria (sollte) fazer, segundo leis da liberdade, mas não faz, é assegurado também [...]

12 V. a esse respeito as observações de Kersting (1994), 212-216: "o problema do estado de natureza é [...] um problema de âmbito mundial. O silogismo do argumento contratualista abrange correspondentemente todo o mundo. A conclusão não deve recuar para aquém das premissas [...]. O contrato social é necessariamente um contrato da sociedade mundial; a forma de organização política fundada nele objetiva um Estado mundial" (213).

13 Do ponto de vista lógico-especulativo, a Filosofia do Direito tem como objeto a figura historicamente efetivada e institucionalizada da Idéia, ao invés de tentar determinar a figura futura da Idéia, v. $\S 22$ e obs., bem como prefácio, 26. 
mediante uma coação da natureza, que ele o fará, e, na verdade, de acordo com as três relações do Direito Público: Direito do Estado, Direito das Gentes e Direito Cosmopolita" (EF, B 59).

A obrigação de uma Paz Perpétua (EF, B 51), fundamentada e legitimada pela razão, é, por um lado, negada pelos interesses dos indivíduos e Estados, cujas motivações imediatas não são o dever-ser da instauração da Paz Perpétua. Mas, por outro lado, a guerra motivada pelos conflitos de interesses, bem como as conseqüências da guerra, tais como empobrecimento, sofrimento, endividamento, escassez de gêneros alimentícios e obstáculos ao comércio (TP, A 279s; EF, B 52ss), causariam um enfraquecimento generalizado das forças beligerantes, as quais veriam na resolução jurídica dos conflitos uma forma bem menos onerosa para dirimir suas disputas: "aquilo que a boa vontade deveria ter feito, mas não fez, então a impotência finalmente tem de efetivar" (TP, A 280; grifo de LAV). Os efeitos deletérios da guerra, a mediação da qual a natureza se serve (EF, B 57), a fim de que o Direito finalmente receba o comando das relações interindividuais e interestatais (EF, B 62), minaria progressivamente o ímpeto beligerante dos Estados, conduzindo-os lenta, sofrida, mas seguramente até àquele momento da história em que o éthos da pax perpetua pudesse definitivamente estender-se por todo o orbe planetário.

Ora, essa reflexão de Kant não está muito longe da de Hegel, como veremos mais abaixo, levando em consideração, naturalmente, as devidas diferenças entre ambos.

Volto, por ora, ao tópico do desfecho do estado de guerra nos dois casos: ${ }^{14}$ (1) na relação entre os indivíduos e (2) na relação entre os Estados. Enquanto os indivíduos encontram, no Estado, uma resolução baseada no Direito para seus respectivos conflitos - Direito este que tem a força para se impor com justiça diante das partes contenciosas, o Direito, que se faz prevalecer no cenário da história mundial não é o Direito de povos particulares, justamente porque estes são realidades finitas, limitadas e "ideais"( § 341), i. é, destinadas a ser ultrapassadas mais cedo ou mais tarde. Se (1) a resolução legal dos conflitos entre os Estados é um dever-ser; se (2) a guerra é o estado da ausência do Direito, ausência de um poder suficientemente forte e reconhecido, capaz de apontar o que é de direito e impor sua decisão às partes conflitantes, mesmo que um mínimo de Direitos das Gentes deva ainda continuar existindo na guerra, para viabilizar a futura paz (§ 338), o que já havia sido exigido também por Kant no sexto artigo preliminar de Para a Paz Perpétua; se (3) a relação entre os Estados também admite um "jogo" de "violência" e "injustiça" (§ 340), então falar em Direito, na história mundial, só tem sentido, aos olhos de Hegel, se há (1) um tribunal de alcance e competência mundiais, capaz de implementá-lo, ao mesmo tempo que haja (2) alguém que exerça o papel de juiz nesse tribunal.

Este alguém é "o espírito universal, o espírito do mundo" ou, ainda, "o pretor superior", e o "tribunal mundial", por sua vez, é a história mundial (§ 339, adendo; $\S 340)$.

14 Outra distinção importante entre indivíduos e os Estados diz respeito ao respectivo bem-estar (Wohl) deles (§ 337). 


\section{A história mundial}

A entrada em cena do espírito do mundo pode parecer abrupta, tal como exposta aqui, mas ela é o resultado de uma longa preparação. Em primeiro lugar, vale lembrar que a vinculação entre Direito e espírito já é feita logo no $\S 4$ da introdução à Filosofia do Direito. Em segundo lugar, vale também lembrar o significado do termo "Direito" para Hegel. Sendo uma "parte da filosofia" (§ 2), a Ciência do Direito lida com "o direito natural ou o direito filosófico", o qual deve ser distinguido do direito positivo. Aquele não se propõe produzir "um código positivo de leis" indispensável para "o Estado efetivo" (§ 3, obs.), mas ser um critério ou medida de avaliação dos códigos de lei historicamente existentes. O objeto do direito filosoficamente considerado é "o sistema do Direito, o reino da liberdade efetivada, o mundo do espírito produzido a partir dele mesmo, enquanto uma segunda natureza" (§ 4; grifo de LAV). Portanto, o Direito, obra do espírito na sua face objetiva, abrange todas as suas manifestações nessa esfera, a saber, o direito abstrato, a moralidade, a família, a sociedade civil, o Estado e, por fim, a história mundial, enquanto todos eles representam o "existir (Dasein) da vontade livre" (§ 29). Todas essas estações constituem momentos do mundo produzido pelo espírito e, enquanto tais, etapas parciais e limitadas da liberdade realizada. Conseqüentemente, o mundo do espírito encontra, na história mundial, obra do espírito do mundo, o seu Direito supremo - o Direito do espírito do mundo, i. é, a liberdade efetivada no seu grau mais elevado na esfera do espírito objetivo (§ 340).

Como conseqüência, o Direito do espírito do mundo se afirma a partir da "dialética fenomenal da finitude desses espíritos" (os espíritos dos povos; acréscimo de LAV) (§ 340). Isto significa que o Direito do espírito do mundo a ser efetivado na história mundial, enquanto tribunal mundial, apontará as limitações do Direito, tal como ele se concretiza materialmente, nos diversos espíritos dos povos, "mediante $\mathrm{o}$ caráter nacional particular de um povo, o nível de seu desenvolvimento histórico" (§ 3). ${ }^{15}$ A limitação do Direito, realizado nos diversos e particulares espíritos dos povos, será, enfim, a sentença expressa no tribunal da história mundial. ${ }^{16}$ Ao mesmo tempo que o grau de realização da liberdade efetiva é elogiado, naquele específico espírito do povo, e este é o aspecto positivo desse julgamento, as deficiências desse grau são também identificadas, e, como conseqüência, aquele espírito do povo, enquanto representava, até então, o estágio mais avançado da realização da liberdade, é abandonado pelo espírito do mundo. A tocha da liberdade será conduzida, então, pelo espírito de um outro povo.

Em terceiro e último lugar, deve-se perguntar pelo Direito que o espírito do mundo leva a cabo na história mundial enquanto tribunal do mundo. Ora, o Direito que compete ao espírito do mundo é ser o que ele é. O que ele é, "seu ser e prin-

$\overline{15}$ V. § 3, obs., no qual Hegel comenta a diferença entre "desenvolvimento a partir do conceito" de Direito e "esclarecimento e justificação históricas". Este parágrafo pode ajudar a entender aquela afirmação de Hegel, fonte de tanta discussão: "aquilo que é racional é efetivo; aquilo que é efetivo 16 é racional" (Prefácio, 24).

16 Este tribunal, no entanto, não deve ser entendido como um "destino cego" (§ 342). 
cípio" (§ 343), é o desenvolvimento prático e cognitivo de si mesmo, de tal forma que, mediante sua ação (seine Tat) na história mundial, ele obtenha o conhecimento de si (§ 352).

É este justamente o ponto que articula o conhece-te a ti mesmo (§ 343 , obs) do espírito do mundo com a "dialética fenomenal da finitude" dos espíritos dos povos (§ 340). De um lado, o espírito do mundo desenvolve o saber que ele tem de si mesmo em e através do saber que um específico espírito de um povo possui acerca do que ele - este particular espírito de um povo - é. Principalmente no caso daquele povo que consegue expressar com mais acuidade a face mais avançada do espírito do mundo na sua época e, em razão disso, tornar-se "o dominante" e ser "o suporte do nível presente de desenvolvimento do espírito do mundo" (§ 347) naquela época, então há, de fato, uma profunda interpenetração entre a universalidade do espírito do mundo e a particularidade desse determinado espírito do povo, de tal forma que este possui "seu Direito absoluto" ( $\S \S 345,347$ ) de se impor diante de outros povos; pois justamente ele, assim como antes dele e posteriormente outros após ele, são "instrumentos inconscientes e membros daquele negócio interno" (§ 344), a saber, "do movimento de sua [do espírito do mundo; adendo de LAV] atividade de se conhecer absolutamente, de, com isso, libertar sua consciência da forma da imediatidade natural e vir a si mesmo" (§ 352). De outro lado, no entanto, o espírito do mundo não se esgota ou se exaure nas formas finitas de suas manifestações, já que ele as transcende, na medida mesma em que é imanente a todas elas. Como Hegel já havia apontado nos famosos §§ 5 a 7 da introdução, ao abordar a dialética da vontade, a liberdade não é a indeterminidade, também não é determinidade. Ela é ambas (§ 7, adendo). ${ }^{17}$ Ora, o espírito do mundo é a liberdade que se desdobra na história mundial (§ 342), e, neste sentido, retomando aquilo que Hegel dizia acerca da vontade na introdução à Filosofia do Direito, ele é "a atividade que se mediatiza em si e retorna a si” (§ 7, obs), a qual, portanto, em sua inquietação, nunca encontra um repouso definitivo em uma estação particular do seu périplo de autoconhecimento, até que ele alcance o conhecimento completo de si mesmo.

Ora, aquilo que, em Kant, a natureza providencialmente compreendida, mediante a guerra, leva a cabo, a saber, a progressiva institucionalização da resolução jurídica de conflitos individuais e interestatais, seja na forma da Federação dos Povos, seja na forma de uma República Mundial, não é entrevisto por Hegel. As guerras entre os povos não os conduziu, assim pensa Hegel, até àquela época em que ele elabora sua filosofia da história, a uma Federação dos Povos ou a uma República Mundial, seja porque, no primeiro caso, o seu fundamento é algo contingente e precário, seja porque, no segundo caso, os Estados perderiam sua soberania, eles que são o "poder absoluto na terra". Elas, as guerras, e os conflitos menos onerosos, aquela já citada dialética dos espíritos dos povos, propiciam o avançar da resolução legal das disputas entre indivíduos e entre Estados, avançar este incorporado em um determinado espírito do povo, de acordo com a época em questão, e sua extensão

17 Como lembra Hegel neste § 7, obs., aqui reside "o verdadeiro e especulativo (e todo verdadeiro [...] pode ser pensado apenas especulativamente)". 
gradual a outros povos, seja por meios irênicos, seja por meios bélicos. Kant vislumbrou o futuro da humanidade, projetado pela razão em seu uso prático-moral, em uma convivência racional entre os povos na forma de uma Federação dos Povos ou República Mundial, ao passo que Hegel, fincando pé na efetividade do devir histórico, contemplou a realização da liberdade, tal como ela, de fato, aos seus olhos, alcançou sua institucionalização na pluralidade das humanidades de nosso planeta, procurando identificar as formas mais desenvolvidas da experiência individual e coletiva da liberdade.

\section{Os quatro reinos da história mundial}

Organizado em quatro grandes estações, a saber, (1) o reino oriental, (2) o reino grego, (3) o reino romano e (4) o reino germânico, o autoconhecimento do espírito em suas manifestações nos diversos espíritos dos povos articula (a) o subjetivo e o objetivo, (b) o humano e o divino, (c) o singular e o universal, (d) o mundano e o espiritual, (e) o indivíduo e a substância, (f) o finito e o infinito.

A primeira estação é caracterizada pela imersão da singularidade na universalidade, de tal forma que o reconhecimento dos direitos da individualidade é negado em detrimento da absoluta validade da substância espiritual e daquele que a representa. Ela assinala aquela etapa da história mundial, na qual a totalidade éticoespiritual, identificada com o divino, não deixa espaço para a emergência da subjetividade. Assim sendo, o governo se apresenta como uma teocracia, de acordo com a qual o governante é a própria divindade ou seu representante supremo na terra. Essa unidade ainda imediata entre substância e sujeito transforma a religião na própria legislação e os costumes religiosos em leis do Estado. Ao mesmo tempo que, por um lado, a ordenação social se naturaliza e petrifica na forma de castas, por outro lado, nada pode estar fixo diante do poder arbítrário do governante.

A segunda estação do périplo do espírito do mundo já configura uma diferenciação entre o universal e o singular, tendo como conseqüência, por um lado, a emergência do princípio da individualidade, bem como dos seus direitos, e, por outro lado, a universalidade ético-espiritual se configurando como a esfera positiva da realização daquela individualidade. Essa primeira diferenciação, todavia, carrega consigo deficiências, já que o aspecto subjetivo, em primeiro lugar, não foi totalmente reconhecido, tal como o atesta a existência da escravidão, no mundo grego e, em segundo lugar, a autodeterminação da vontade ainda se apóia em um poder que lhe é alheio e estranho, tal como o testifica a consulta aos oráculos, aos espíritos protetores, às entranhas dos animais e aos vôos dos pássaros, ${ }^{18}$ a fim de que uma decisão seja tomada. Além disso, há também uma fragmentação da substância éticoespiritual, dando origem, por essa razão, àquela multiplicidade de cidades que eram também Estados. Esse déficit, contudo, não impede Hegel de qualificar esta agora diferenciada unidade entre finito e infinito, no lado subjetivo, como "a bela individualidade ética” (§ 353) e, do lado objetivo, como “eticidade livre e alegre” (§ 356).

18 Hegel se refere ao $\S 279$, obs. 
A terceira estação marca a passagem da diferenciação para a dissociação, de tal forma que sujeito e objeto, singular e universal, indivíduo e Estado se isolam em suas respectivas unilateralidades, aprofundando progressivamente a sua oposição na direção de uma "dilaceração infinita" (§ 357). Em contraposição à gaia eticidade grega, o mundo romano aparece como uma eticidade sombria e lúgubre. A dissociação é marcada, pois, pelo dualismo da "afirmação de um poder frio e ávido" e pela "perversidade da plebe" (§ 357). O lado objetivo-universal (os povos submetidos à violência do poder romano) é unificado abstrata, formal e forçosamente no panteão, enquanto os indivíduos tornam-se também abstrata, formal e forçosamente iguais enquanto pessoas privadas. Entre eles há um espaço, o qual os indivíduos não reconhecem como esfera de sua realização ética e o qual o poder romano, por sua vez, utiliza como área de imposição do seu mando.

Dessa profunda dilaceração nasce a quarta estação do devir do espírito do mundo, enquanto ela é a reconciliação (Versöhnung, § 359) daquela cisão tão profunda da estação anterior. Primeiramente, uma reconciliação na forma da "fé, amor e esperança”, a reconciliação subjetivo-religiosa e cristã (§ 359). Posteriormente, ela também avança para a esfera objetiva, "o reino mundano" (§ 359), permitindo àquelas nações, que abraçaram ambas as reconciliações, desenvolver suas instituições, tendo em vista a observância dos direitos do singular e do universal, do indivíduo e do Estado. O mundo germânico, tanto no campo subjetivo quanto no objetivo, aos olhos de Hegel, é a exemplificação do movimento de recíproca interpenetração entre o espiritual (das Geistliche) e o mundano (das Weltliche), de tal forma que esta quarta e última estação leva a cabo o que as outras não conseguiram: a inserção do espiritual "no aquém terreno e na mundanidade comum" (§ 360), ao passo que o mundano se eleva "ao pensamento, ao princípio do ser e do saber racionais e à racionalidade do Direito e da lei" (§ 360). Abandonando sua unidade abstrata, percorrendo a dor da diferenciação e da dilaceração, o espírito retorna a si como unidade diferenciada ou diferença unificada. Foi justamente essa reconciliação entre o espiritual e o humano, o subjetivo e o objetivo, o singular e o universal, o sujeito e a substância, que a Filosofia do Direito procurou expor no direito abstrato, na moralidade e, finalmente, na eticidade.

\section{Hegel, Kant e os séculos XX e XXI}

Levando em consideração as teses de Hegel e Kant, e tendo como pano de fundo, principalmente, o século XX, há pouco encerrado e avançando pelos dois primeiros anos do século XXI, poderíamos nos perguntar sobre a pertinência dessas mesmas teses. Para tanto, gostaria de tomar como referência principal, acerca da guerra e paz, a análise de Hobsbawm sobre o cenário internacional nos séculos XX e XXI.

Hobsbawm apresenta uma constatação que confirma o diagnóstico já feito há cerca de duzentos anos por Hegel e Kant: "Há agora, como houve por todo o século XX, a completa ausência de toda autoridade global efetiva, capaz de controlar ou resolver disputas armadas". ${ }^{19}$ Não havendo um global judge e um global court of

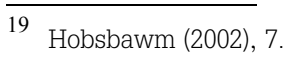


law, a guerra torna-se o instrumento mais freqüente para resolver disputas. Daí, portanto, a triste conclusão do autor acerca de um século, que aliou uma forma tradicional e onerosa de resolução de antagonismos ao poder científico-tecnológico: "O século XX foi o mais assassino na história registrada [...] O mundo como um todo não tem estado em paz desde 1914 e não está em paz agora". ${ }^{20}$ Diante de um quadro tão sombrio como este, ainda nos situamos naquilo que Hegel e Kant qualificavam como o estado de natureza entre os Estados: o reino da violência, o qual, no entanto, de acordo com o otimismo de ambos, é a face negativa que leva a humanidade à positividade da liberdade realizada e, portanto, institucionalizada.

Mesmo a Liga das Nações, fundada em 1919, a partir das trágicas experiências da primeira guerra mundial, e a Organização das Nações Unidas, fundada em 1945 como resultado da ineficácia das Liga das Nações, para enfrentar as querelas entre os Estados, inexistentes ao tempo de Kant e Hegel, as quais poderiam ser aproximadas ao que Kant denominou uma Federação de Povos, não conseguiram estabelecer a Paz Perpétua no estilo pensado por Kant. Atualmente, mesmo com a presença da Organização das Nações Unidas e de outros organismos internacionais, "o gerenciamento da paz e da guerra tem sido improvisado". ${ }^{21}$ E certamente um improviso que deixa os flancos abertos para formas antigas, modernas e pósmodernas de violência.

Ainda é importante detectar as condições específicas da condução da guerra bem como as condições específicas da distinção entre guerra e paz, neste século e no passado, distintas daquelas que vigiam ao tempo de Hegel e Kant.

Uma consideração importante diz respeito à substituição das relativamente claras determinações das Convenções de Haia, de 1899 e 1907, ainda respeitadas durante a primeira guerra mundial, por uma confusão que dificulta (1) distinguir conflitos intra-estatais e interestatais e (2), o que é talvez a conseqüência mais grave, distinguir entre guerra e paz. ${ }^{22}$

Relativamente ao primeiro ponto, Hobsbawm chama a atenção para o fato de que o século XX foi um século de fragmentação e esboroamento de impérios, que levaram a uma reordenação do jogo político internacional, de tal forma que os atores envolvidos não poderiam ficar inertes diante dessas mudanças, caso quisessem manter ou aumentar seu poder de mando. Conseqüentemente, os limites entre guerras internacionais e civis tornaram-se bastante voláteis, contrariando, pelo menos do ponto de vista de Kant, o quinto artigo preliminar para o estabelecimento de uma Paz Perpétua, uma vez que a constituição e o governo dos Estados mais fracos e, portanto, mais suscetíveis de cair sob o domínio dos mais fortes, não são respeitados, ao passo que, do ponto de vista de Hegel, a "dialética" entre os Estados, diante da ausência de uma autoridade global, não poderia apresentar um resultado diferente.

20 Idem, 5

21 Idem, 5.

22 Idem, 6. 
Particularmente inquietante é o obscurecimento da distinção entre guerra e paz. A segunda guerra mundial, além de ter sido uma guerra que enfraqueceu os códigos de guerra estabelecidos pelas Convenções de Haia, foi seguida por um período, no qual tornou-se difícil qualificá-lo como um período de guerra ou um de paz, de tal forma que a expressão "guerra fria" traz à luz esta indeterminação: nem "guerra" nem "paz". ${ }^{23}$ Mesmo após o fim da guerra fria, a situação de indefinição é ilustrada pela situação do Iraque, depois do fim formal da guerra do Golfo, já que o país ainda é objeto de bombardeios, embora não oficialmente em guerra. Também exemplificam essa situação o conflito entre israelenses e palestinos, bem como o antagonismo entre Israel, de um lado, e Líbano e Síria, de outro. Esse obscurecimento é, em parte, motivado pelo caráter de cruzada que tomou conta dos atores beligerantes, opondo-os na forma de ideologias irreconciliáveis, das quais resultam objetivos não sujeitos à negociação e "rendição incondicional". Onde reinam esse espírito de cruzada e aquela indeterminação, as chances de uma resolução legal de conflitos são praticamente nulas.

Além disso, outro problema aparece, quando o termo "guerra" é estendido para designar a luta contra aquilo que um determinado Estado considera como contrário aos seus interesses: guerra contra o narcotráfico, guerra contra o terrorismo, guerra contra o crime organizado, guerra contra a corrupção, guerra contra movimentos separatistas dentro das fronteiras nacionais, etc. A distinção entre força de soldados, cujo objetivo é a vitória sobre outras forças armadas, embora essa meta não tenha uma conotação necessariamente moral, e força de polícia, cujo objetivo é manter ou restaurar a ordem pública, aqui, com uma conotação nitidamente moral de fazer justiça, é mais fácil de ser traçada no campo teórico do que na arena prática. Hobsbawm cita como exemplo um membro do Exército Republicano Irlandês (IRA), que se vê como beligerante e, portanto, em estado de guerra, embora um oficial da lei do Reino Unido o considere como um assassino. Um homicídio perpetrado por um membro do IRA, enquanto este é tomado como soldado de um exército em batalha, não é em si crime, na medida em que ele é interpretado como um combatente no campo de batalha, ao passo que o oficial da lei do Reino Unido o qualifica como violador da lei, ${ }^{24}$ pois suas ações são compreendidas como ruptura da ordem legal e pública, em uma província do Reino Unido. O resultado a que se chegou, "uma extensa ausência de luta", confirma a volatilidade das fronteiras entre guerra e paz. Estamos diante de uma situação paradoxal. Ao mesmo tempo que as condições preliminares e definitivas para o estabelecimento da Paz Perpétua são colocadas em questão, juntamente com o enfraquecimento dos procedimentos para a condução da guerra e restabelecimento da paz, preconizados pelas Convenções de Haia, aquelas condições e esses procedimentos devem ser reforçados, a fim de que o prolongamento dessa indeterminação entre guerra e paz não termine por produzir um ambiente cultural hostil ao estabelecimento de uma verdadeira paz.

23 Idem, 6 .

24 Idem, 6s. 
Ora, se o estado de natureza não é totalmente domesticado, dentro das próprias fronteiras nacionais, melhor não está a situação na esfera internacional, principalmente quando se levam em conta os conflitos bélicos entre organizações estatais e não-estatais, ao que me parece, não contemplados por Hegel e Kant, ambos debruçados somente sobre os conflitos entre Estados.

Além dos conflitos entre Estados, há de se considerar também um ingrediente recente complicador da paz: a beligerância entre Estados e organizações não-estatais. De um lado, percebe-se "uma grande diferença entre o século XXI e o XX: a idéia de que a guerra acontece em um mundo dividido em áreas territoriais sob a autoridade de governos efetivos que possuem o monopólio dos meios de poder e de coerção públicos deixou de se aplicar”. De outro lado, nos "últimos 30 anos [...] o Estado territorial tem, por várias razões, perdido seu monopólio tradicional da força armada, muito de sua prévia estabilidade e de seu poder e, cada vez mais, de seu sentimento fundamental de legitimidade ou pelo menos de permanência aceita". ${ }^{25}$ Acrescente-se a isso a maior facilidade de acesso às armas, bem como maior disponibilidade de financiamento da guerra. ${ }^{26}$ Todos esses fatores facilitaram a formação de grupos não-estatais bélicos, sem uma representação executiva de poder no estilo tradicional. Bastante ilustrativa a esse respeito é a grande dificuldade experimentada pela superpotência USA, a qual, em uma leitura à la Hegel, poderia ser denominada como a encarnação contemporânea do que ele chamava de espírito do mundo, para combater a organização Al Qaeda. Ora, raciocinando dentro dos limites da argumentação de Hegel e Kant, a existência dessas organizações não-estatais e a mudança de equilíbrio nas relações entre elas e os Estados demonstram a persistência e insistência do estado de natureza dentro do Estado e nas relações entre os Estados. Tal situação evidencia mais uma vez a estreita e indissolúvel interconexão entre a paz intra-estatal e a paz interestatal, como já havia demonstrado o argumento do contrato social, acima discutido. O aumento crescente do intercâmbio entre as nações, nos mais diferentes setores, apenas reforçou essa ligação.

Como um agravante a todo esse quadro, a recusa dos USA de ratificar o tratado que cria o Tribunal Penal Internacional permanente, ${ }^{27}$ ao qual poderiam ser conduzidos militares, diplomatas e líderes políticos norte-americanos, não deixa de ser um desestímulo à Paz Perpétua, ao mesmo tempo que tal atitude faz lembrar aquele "direito absoluto" do povo que, em determinada época, representa a fase mais avançada do espírito do mundo, pois, diante de tal direito, "os espíritos dos outros povos são privados de direito (rechtlos)" (§ 347) e sujeitos ao seu avassalador poderio.

25 Idem, 8

Outra observação importante diz respeito, em determinados casos, (1) ao desaparecimento virtual do Estado e (2) ao questionamento do poder do próprio Estado em áreas de sua competência legal, sendo forçado ou a disputar belicamente o controle dessas áreas, ou a lutar pela reconquista das mesmas.

27 Folha de São Paulo, 06/05/2002, A 9. 
Não por acaso, Hobsbawm, se bem que com aquele cuidado esperado, arrisca uma previsão: "A perspectiva de um século de paz é remota" ${ }^{28}$ Penso que, no final do século XVIII e início do século XIX, quando Kant redigiu Para a Paz Perpétua, e Hegel, as Linhas fundamentais da Filosofia do Direito, respectivamente, as perspectivas, com muita probabilidade, não eram diferentes. Evidentemente, qualquer pessoa sensata não teria dúvidas em aceitar a tese de Hegel e Kant, segundo a qual o Direito, enquanto liberdade realizada e institucionalizada, é a forma racional e garantidora da paz interna e paz externa. Também, evidentemente, qualquer pessoa sensata não deixaria de reconhecer os imensos obstáculos que precisam ser transpostos para o estabelecimento da Paz Perpétua, seja lá qual for a forma assumida por ela, uma vez que ela, sucedendo e substituindo aquela dialética cruenta entre os Estados, não é apenas o desejo desesperado de uma humanidade tão sofrida, embora, infelizmente, sempre disposta para novos embates bélicos, mas o racionalmente posto como nosso dever-ser, apesar de e mesmo justamente em razão de todas as evidências capazes de fazer a Paz Perpétua parecer uma quimera. Ainda vivenciando uma federação de nações incapaz de promover efetivamente uma resolução legal dos seus conflitos e, portanto, sujeitas àquela "dialética", que as joga umas contra as outras, resta-nos, contudo, a esperança, baseada no que a razão pode nos mostrar, de que aquilo que já é evidenciado por essa mesma razão seja efetivado por e apesar de todos os acidentes e percalços de nossa práxis. Que a formulação kantiana, no estilo platônico-demiúrgico, nos sirva de estrela-guia: "a razão [...] não segue a ordem das coisas, tal como elas se apresentam no fenômeno, mas faz para si, com inteira espontaneidade, uma ordem própria, segundo idéias, às quais ela adapta as condições empíricas, e, segundo as quais, ela declara como necessárias mesmo ações que, no entanto, não aconteceram e, talvez, não acontecerão" ${ }^{29}$

\section{Referências bibliográficas}

GERHARDT, V. Immanuel Kants Entwurf 'zum ewigen Frieden'. Eine Theorie der Politik (Projeto "Para a Paz Perpétua” de Immanuel Kant. Uma teoria da política). Darmstadt: Wissenschaftliche Buchgesellschaft, 1995

HABERMAS, J. Kants Idee des ewigen Friedens - aus dem historischen Abstand von zweihundert Jahren (A idéia kantiana da Paz Perpétua - a partir de uma distância histórica de duzentos anos). In: Lutz-Bachmann, M. und Bohman, J. (Ed.). Kants Friedensidee und das Problem einer neuen Weltordnung (A idéia de paz de Kant e o problema de uma nova ordem mundial). Frankfurt/M.: Suhrkamp, 1996, 7-24.

HEGEL, G. Grundlinien der Philosophie des Rechts oder Naturrecht und Staatswissenschaft im Grundrisse (Linhas fundamentais da Filosofia do Direito ou Direito Natural e Ciência do Estado em esboço). Frankfurt/M.: Suhrkamp, 1991. (Werke 7).

28 Hobsbawm (2002), 10

29 Kant, KrV, B 576. 
Wissenschaft der Logik II (Ciência da Lógica II). Frankfurt/M.: Suhrkamp, 1991. (Werke 6). [Abr.: WL II]

HERRERO, F. Ética em Kant. In: Síntese. V. 28, n. 90, 2001, 17-36.

HOBSBAWM, E. A epidemia da guerra. In: Mais!, 14/04/2002, Folha de São Paulo, São Paulo, 4-10.

KANT, I. Kritik der reinen Vernunft (Crítica da razão pura). Darmstadt: Wissenschaftliche Buchgesellschaft, 1983 (Bände, 3/4). [Abr.: KrV].

Kritik der praktischen Vernunft (Crítica da razão prática). Darmstadt, Wissenschaftliche Buchgesellschaft, 1983 (Band 6). [Abr.: KpV].

Über den Gemeinspruch: Das mag in der Theorie richtig sein, taugt aber nicht für die Praxis (Sobre o adágio: isto pode estar certo na teoria, mas não vale para a prática). In: KANT, I. Schriften zur Anthropologie, Geschichtsphilosophie, Politik und Pädagogik (Escritos sobre antropologia, filosofia da história, política e pedagogia). Darmstadt: Wissenschaftliche Buchgesellschaft, 1983 (Band 9). [Abr.: TP].

Zum ewigen Frieden (Para a Paz Perpétua). In: Kant, I. Schriften zur Anthropologie, Geschichtsphilosophie, Politik und Pädagogik (Escritos sobre antropologia, filosofia da história, política e pedagogia). Darmstadt: Wissenschaftliche Buchgesellschaft, 1983 (Band 9). [Abr.: EF].

KERSTING, W. Die politische Philosophie des Gesellschaftsvertrags (A filosofia politica do contrato social). Darmstadt: Wissenschaftliche Buchgesellschaft, 1994.

LUTZ-BACHMANN, M. e BOHMAN, J. (Eds.). Kants Friedensidee und das Problem einer neuen Weltordnung (A idéia de paz de Kant e o problema de uma nova ordem mundial). Frankfurt/M.: Suhrkamp, 1996.

MERKEL, R.; WITTMANN, R. "Zum ewigen Frieden". Grundlagen, Aktualität und Aussichten einer Idee von Immanuel Kant. ("Para a Paz Perpétua". Fundamentos, atualidade e perspectivas de uma idéia de Immanuel Kant). Frankfurt: Suhrkamp, 1996.

ROHDEN, V. (Ed.) Kant e a instituição da Paz. Porto Alegre: Editora da Universidade/UFRG, GoetheInstitut/ICBA, 1997

VIEIRA, L. Freiheit als Kultus. Aporien und Grenzen der Auffassung der menschlichen Freiheit bei Hegel (Liberdade enquanto culto. Aporias e limites da concepção da liberdade humana em Hegel). Würzburg: Königshausen \& Neumann, 1996. 